\title{
Atoh1 Directs the Formation of Sensory Mosaics and Induces Cell Proliferation in the Postnatal Mammalian Cochlea In Vivo
}

\author{
Michael C. Kelly, ${ }^{1}$ Qing Chang, ${ }^{2}$ Alex Pan, ${ }^{1}$ Xi Lin,,${ }^{1,2}$ and Ping Chen ${ }^{1,2}$ \\ Departments of ${ }^{1}$ Cell Biology and ${ }^{2}$ Otolaryngology, Emory University School of Medicine, Atlanta, Georgia 30322
}

Hearing impairment due to the loss of sensory hair cells is permanent in humans. Considerable interest targets the hair cell differentiation factor Atohl as a potential tool with which to promote hair cell regeneration. We generated a novel mouse model to direct the expression of Atohl in a spatially and temporally specific manner in the postnatal mammalian cochlea to determine the competency of various types of cochlear epithelial cells for hair cell differentiation. Atoh1 can generate cells in young animals with morphological, molecular, and physiological properties reminiscent of hair cells. This competency is cell type specific and progressively restricted with age. Significantly, Atohl induces ectopic sensory patches through Notch signaling to form a cellular mosaic similar to the endogenous sensory epithelia and expansion of the sensory mosaic through the conversion of supporting cells and nonautonomous supporting cell production. Furthermore, Atohl also activates proliferation within the normally postmitotic cochlear epithelium. These results provide insight into the potential and limitations of Atoh1-mediated hair cell regeneration.

\section{Introduction}

The highly specialized sensory hair cells within the inner ear are directly responsible for the conversion of mechanical stimuli to neuronal signals important for both auditory and vestibular function. Whereas some vertebrates retain the ability to regenerate sensory hair cells after damage (Brignull et al., 2009), mammals have only very limited ability to replace missing hair cells (Forge et al., 1993; Warchol et al., 1993; Kelley et al., 1995; Kawamoto et al., 2009), making the associated deficits permanent.

Atoh1 is a proneural basic helix-loop-helix transcription factor required for the differentiation of sensory hair cells from the sensory precursor domains during development (Bermingham et al., 1999; Chen et al., 2002). Previous work has shown that ectopic delivery of Atoh1 to embryonic (Woods et al., 2004; Gubbels et al., 2008) and neonatal (Zheng and Gao, 2000; Shou et al., 2003)

\footnotetext{
Received October 26, 2011; revised February 21, 2012; accepted March 21, 2012.

Author contributions: M.C.K., Q.C., X.L., and P.C. designed research; M.C.K., Q.C., and A.P. performed research; M.C.K., X.L., and P.C. contributed unpublished reagents/analytic tools; M.C.K., Q.C., A.P., X.L., and P.C. analyzed data; M.C.K., Q.C., and P.C. wrote the paper.

This work was supported by National Institutes of Health (NIH)-National Institute on Deafness and Other Communication Disorders Grant R01 DC05213 and in part by the National Basic Research Program of China (973 Program) Grant 2012CB967902 and Natural Science Foundation of China Grant 81028003/H1305 (P.C.), and NIH-National Institute of General Medical Sciences Training Grant 5T32GM008605-12 (M.K.). The study was supported in part by the Neuronal Imaging Core of the Emory Neuroscience National Institute of Neurological Disorders and Stroke Core Facilities grant (P30NS055077). The Emory transgenic core staff assisted with generation of the $T g^{A t o h}$ mouse line. We thank the members of the Chen laboratory for helpful discussion, Dr. Yibo Huang for assistance with some of the experiments, Dr. Amy Kiernan for advice on doxycycline administration, Dr. James Bartle for the Espin antibody, and Dr. Jian Zuo and Dr. Zhiyong Liu for critical review of the manuscript.

The authors declare no competing financial interests.

Correspondence should be addressed to Ping Chen, Department of Cell Biology, Emory University, 615 Michael Street, Atlanta, GA 30322. E-mail: ping.chen@emory.edu.

DOI:10.1523/JNEUROSCI.5420-11.2012

Copyright $\odot 2012$ the authors $\quad 0270-6474 / 12 / 326699-12 \$ 15.00 / 0$
}

cochlear epithelia can generate new sensory hair cells. Furthermore, evidence from viral transfection suggests that Atoh1 can direct the formation of new hair cells in the adult mammalian cochlea (Kawamoto et al., 2003; Izumikawa et al., 2005). Consequently, Atoh1 has been an important target for hair cell regeneration strategies (Brigande and Heller, 2009; Shibata and Raphael, 2010).

Despite these promising findings and a tremendous effort in targeting Atoh1, critical evaluation of the efficiency and broader effects of using Atoh1 for hair cell regeneration in the inner ear is still missing (Shibata and Raphael, 2010). The competency of various types of cochlear cells for functional hair cell differentiation on Atoh1 activation has yet to be tested systematically. Furthermore, the structural and physiological consequences of Atoh1-mediated hair cell regeneration aimed at converting any of the cochlear cell populations have not been assessed.

Here, we report the generation of a transgenic mouse line that allows for temporal and cell-specific targeting of Atoh 1 in a stable and reproducible manner. We show that at postnatal stages, the cells in the cochlear lining competent to become hair cells are clustered in distinct regions in neonatal animals and that the competency becomes progressively more restricted up to the age of hearing onset, correlating with the expression of Sox2. Atoh1 initiates a differentiation program that leads to the development of characteristic hair bundles, targeted innervation, and the physiological properties resembling those of endogenous hair cells. Furthermore, the induction of Atoh1 resulted in the upregulation of Notch signaling and the generation of nonsensory supporting cells to encircle the ectopic hair cells in the ectopic sensory regions. In addition, $\mathrm{Tg}^{\text {Atohl }}$ expression induces the expansion of the sensory mosaic through the conversion of supporting cells and nonautonomous supporting cell production. Surprisingly, 

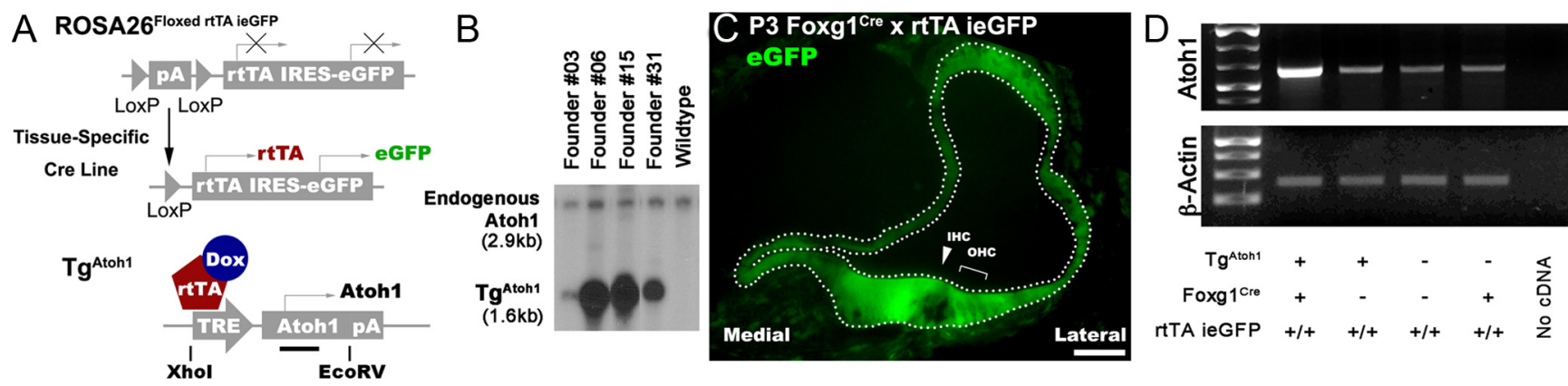

Figure 1. Generation of an inducible tissue-specific Atoh1 transgenic mouse line. $A$, Schematic diagram of the triallelic $T g^{A t o h 1}$ mouse line. When crossed to a Cre mouse line, expression of rtTA (and an eGFP reporter) is tissue specific, determined by Cre recombinase-mediated excision of an upstream stop cassette. Expression of $T g^{\text {Atoh } 1}$ is regulated by TRE, which is activated when rtTA is bound to Dox. Restriction enzyme sites and the probe location for Southern blot are shown. B, As confirmed by Southern blot analysis using an Atoh 1 probe, four transgenic founders carry $T g^{A t o h 1}$. Compared with the endogenous Atoh1 DNA fragment ( $2.9 \mathrm{~kb}$ ), line 3 is estimated to have $2-3$ copies of the $T g^{\text {Atoh }}$ transgene (1.6 kb). C, The expression of eGFP and, presumably, rtTA is ubiquitous in cochlear epithelial cells (marked with dotted lines) when the Foxg1 ${ }^{\text {Cre }}$ line is used to generate triallelic $\operatorname{Tg}^{\text {Atoht }}$ animals or Foxg $1^{\text {Cre }} ; r t T A ; g^{A t o h 1}$ animals. Scale bar, $20 \mu \mathrm{m}$. D, After $2 \mathrm{~d}$ of Dox administration, only in animals carrying $\mathrm{Tg}^{\text {Atoh } 1}$ and alleles for Foxg $1^{\text {Cre }}$ and $r t T A$, the Atoh1 transcript is highly upregulated in the cochlear epithelium as shown with RT-PCR. IRES, Internal ribosome entry site.
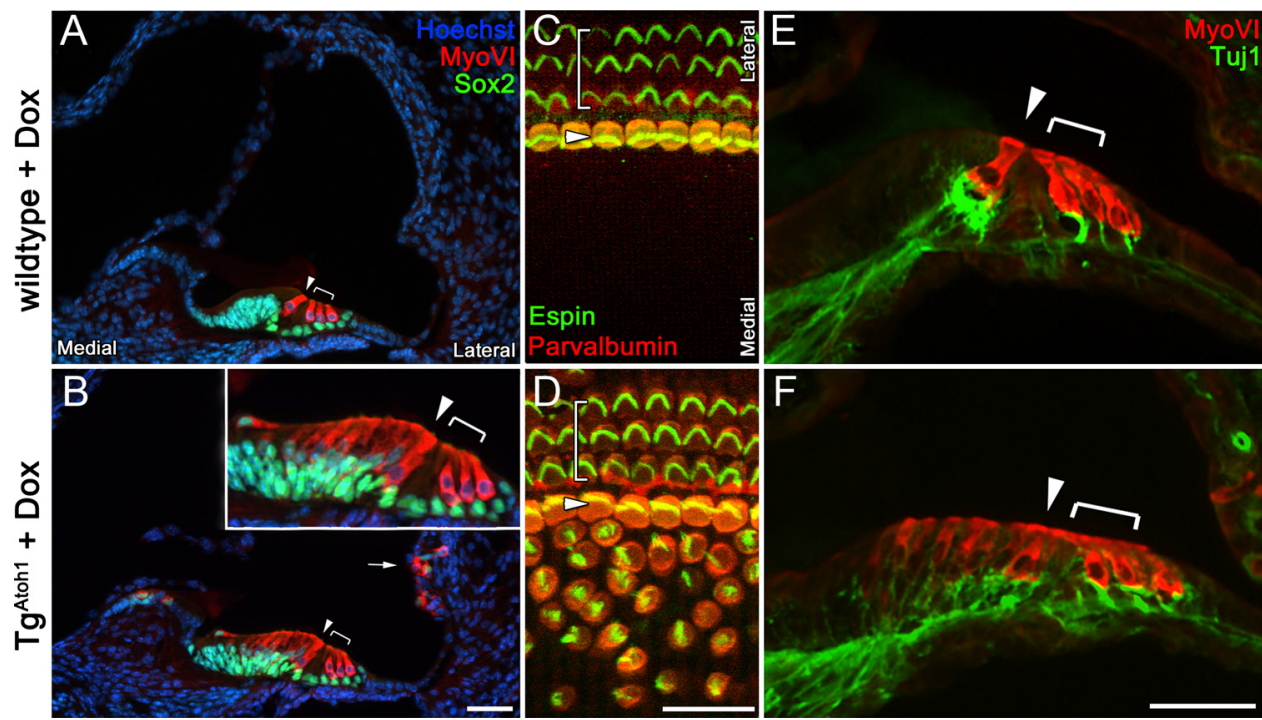

Figure 2. Atoh1 induces patterned ectopic sensory regions consisting of cells with characteristic hair bundles. $A, B$, Compared with littermate controls administered Dox from P1-P3 and examined at P6 $(\boldsymbol{A})$, cross sections through the medial turn of triallelic $\operatorname{Tg}^{\text {Atoh } 1}$ cochlea $(\boldsymbol{B})$ show a large number of MyoVI-positive hair cells generated within Kölliker's organ, which is medial to the endogenous one row of inner (arrowheads) and three rows of outer (brackets) hair cells. MyoVI-positive hair cells are also observed on the lateral wall of the duct (arrows). Note that Sox2-positive cells remain within Kölliker's organ but have an inverse relationship with MyoVI-positive expression in the ectopic hair cells ( $\boldsymbol{B}$, inset). Sox 2 is also induced in the lateral wall of the duct ( $\boldsymbol{B}$, arrows). C, D, Espin-positive stereocilia bundles are observed as polarized arrays on the apical surfaces of the inner (arrowheads) and outer (brackets) hair cells within the organ of Corti (C). Parvalbuminpositive ectopic hair cells medial to the organ of Corti display similar Espin-positive stereocilia bundles that are randomly oriented (D). Ectopic hair cells are surrounded by cells without stereocilia. $\boldsymbol{E}, \boldsymbol{F}$, Tuj1-immunostained neuronal fibers innervated the sensory hair cells of the organ of Corti in wild-type littermates and have no fibers within Kölliker's organ $(\boldsymbol{E})$, whereas ectopic hair cells in Kölliker's organ have Tuj1-positive fibers surrounding their basolateral surfaces in triallelic $\operatorname{Tg}^{\text {Atoh1 }}$ animals $(\boldsymbol{F})$. Scale bars: $\boldsymbol{B}($ for $\boldsymbol{A}, \boldsymbol{B}), \boldsymbol{D}($ for $\boldsymbol{C}, \boldsymbol{D}), \boldsymbol{F}($ for $\boldsymbol{E}, \boldsymbol{F}), 20 \mu \mathrm{m}$.

we observed induced cell proliferation in the normally quiescent cochlear epithelium. These data together suggest that Atoh1 not only acts as a potent hair cell differentiation factor but also activates pathways important for patterning the sensory epithelium through cell fate decisions and cell cycle control.

\section{Materials and Methods}

Generation of inducible transgenic Atoh1 line, induction of Atoh1, and care of animals. The coding sequence for Atohl was cloned into the SalI/ EcoRV site of the pTET-Splice vector (Invitrogen). The vector was linearized by SapI/NotI digest, and founder animals were generated by pronuclear injection. Positive male and female founders were identified by PCR genotyping, confirmed by Southern blot analysis using a probe that recognizes both wild-type and transgenic loci, and then bred onto a reverse tetracycline trans-activator ( $r t T A$ ) background (JAX Stock 005670; The Jackson Laboratory) (Belteki et al., 2005). Both male and female adult mice were crossed to one of the tissue-specific Cre lines (Foxg1 ${ }^{\text {Cre }}$, JAX Stock 004337; The Jackson Laboratory) (Hebert and McConnell, 2000) or GFAP ${ }^{\text {Cre }}$, a gift from Ken McCarthy, University of North Carolina, Chapel Hill, NC (Casper and McCarthy, 2006) to generate samples to be used in this study. Animal care and use were in accordance with National Institutes of Health guidelines and were approved by the Animal Care and Use Committee of Emory University.

Cochlear RNA extraction, $c D N A$ synthesis, and semiquantitative RT-PCR. Cochleae were isolated from male and female transgenic and littermate control mice after doxycycline (Dox) administration and were snap frozen in liquid nitrogen; then cells were lysed with QIAshredder columns (Qiagen). Total RNA was isolated and purified using an RNeasy Micro-elute kit (Qiagen). A cDNA library was synthesized using previously described methods (Chen and Segil, 1999). Relative template representation was then determined after normalization of the total cDNA template using specific primers, as follows: Atoh1 (forward) TCTGCTGCATTCTCCCGAGC, (reverse) 
A
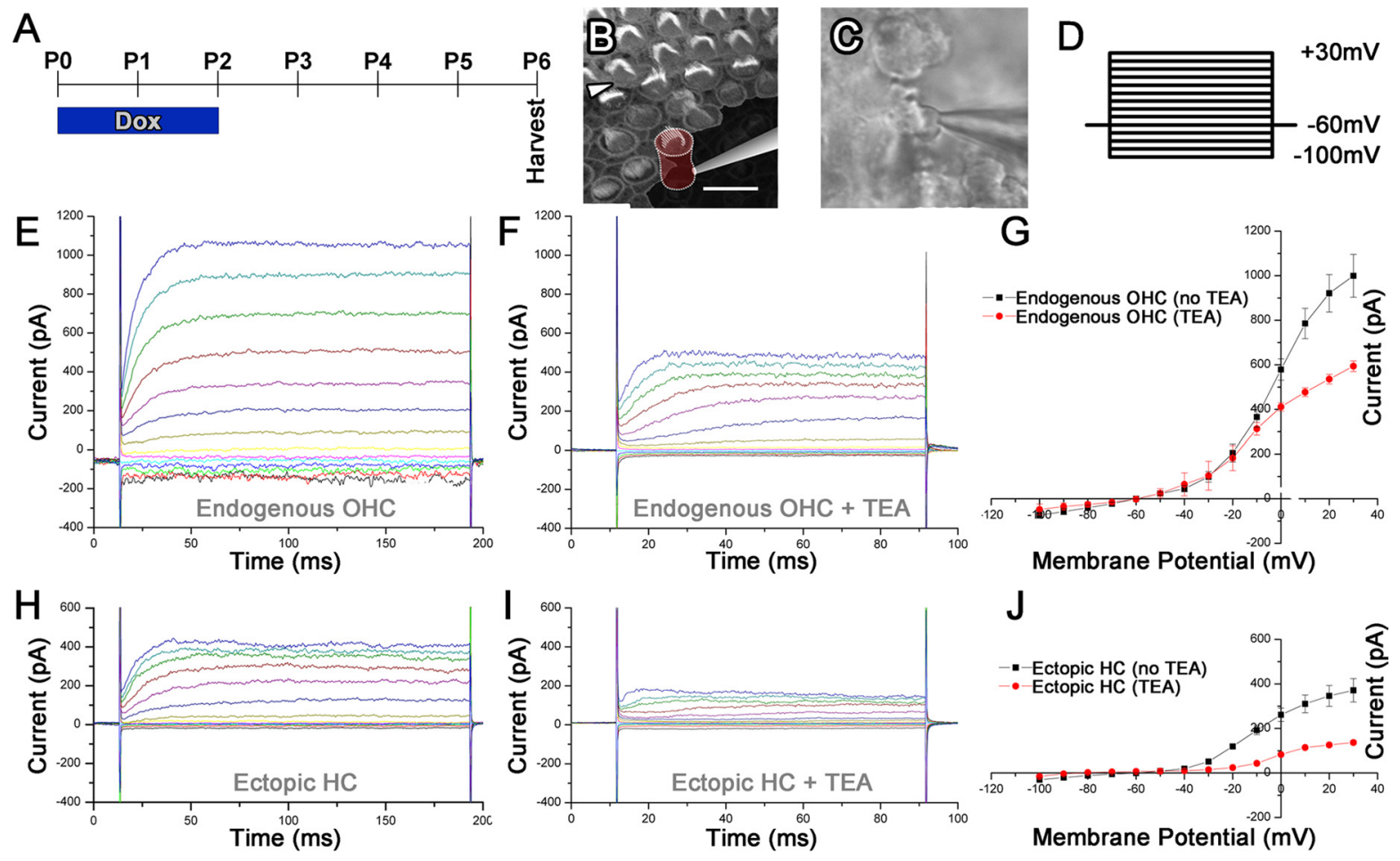

Figure 3. Atoh1 induces ectopic hair cells with voltage-dependent currents. A, Diagram of the $T g^{A \text { Atoh } 1}$ induction protocol used to generate ectopic hair cells in vivo for patch-clamp recordings. $\boldsymbol{B}$, C, The relative position of the patched basolateral surfaces of ectopic hair cells is illustrated (B). Scale bar (in $\boldsymbol{B}$ ), $10 \mu \mathrm{m}$. An example of an actual patched ectopic hair cell is shown (C). D, The voltage steps used for the recording, from -100 to $+30 \mathrm{mV}$. $\boldsymbol{E}-\boldsymbol{G}$, A representative sample set of current traces from an endogenous outer hair cell in normal conditions $(\boldsymbol{E})$ and in solution containing 50 mм TEA $(\boldsymbol{F}) . \boldsymbol{G}$, An $I-V$ plot summarizing the voltage-dependent currents recorded in endogenous outer hair cells under these conditions. $\boldsymbol{H}, \boldsymbol{I}$, A similar representative sample set of current traces from an ectopic hair cell in normal conditions $(\boldsymbol{H})$ and in solution containing $50 \mathrm{~mm} \mathrm{TEA}(\boldsymbol{I})$. $\boldsymbol{J}$, An $I-V$ plot summarizing the voltage-dependent currents recorded in ectopic hair cells under these conditions. More than six individual cells of each type were recorded from tissue from at least two separate animals in normal conditions. Similarly, at least three cells of each type from two separate animals were recorded with TEA. Error bars represent SD. HC, Hair cell; $\mathrm{OHC}$, outer hair cell.

CTCTGGGGGTTACTCGGTGC; Hes1 (forward) AGCGGAATCCCCTGTCTAC, (reverse) CAACTGCATGACCCAGATCA; Hes5 (forward) TCCTCTGGATGTGGGAAGAC, (reverse) CTTTGTATGGGTGGGTGCAT; $\beta$-actin control (forward) GGGACCTGACAGACTACCTC, (reverse) AGCCTTCCTTCTTGGGTATGG.

Organ cultures, Dox induction, and DAPT treatment. For culturing of cochlear explants, $\mathrm{P} 0-\mathrm{P} 4$ stage male and female pups were killed, and cochlear tissue was extracted. The lateral wall, Reissner's membrane, and tectorial membrane were removed before plating on poly-D-lysine (Sigma)-coated glass bottom dishes (MatTek) as reported by Qian et al. (2007). Tissue was incubated in DMEM/F12 (Invitrogen) with 10\% FBS (Atlanta Biologicals), 2\% B-27 supplement (Invitrogen), and 1\% $10^{4}$ $\mathrm{U} / \mathrm{ml}$ penicillin $\mathrm{G}$ (Sigma). DAPT experiments were performed in the absence of FBS. Dox was added to complete culture media for a final concentration of $1 \mu \mathrm{g} / \mathrm{ml}$. For proliferation analysis, BrdU was added to media for a final concentration of $5 \mu \mathrm{g} / \mathrm{ml}$.

Immunostaining/antibodies. Tissue preparation, immunostaining, and imaging were performed as previously described (Li et al., 2008). Primary antibodies used were as follows: myosin VI (MyoVI) antibody (Proteus Biosciences), Sox2 (Santa Cruz Biotechnology), Espin (a gift from J. Bartles, Northwestern University, Evanston, IL), parvalbumin (Sigma), Tuj1 (Covance), BrdU (Roche), GFP (Millipore), Cdkn1b (p27/Kip1) (BD Transduction Laboratories), and phosphohistone H3 (Millipore). Hoechst stain (Invitrogen) was used to mark cell nuclei. BrdU and Cdkn $1 \mathrm{~b}$ staining required a $10 \mathrm{~mm}$ citrate buffer steaming antigen retrieval step (Chen and Segil, 1999; Tang et al., 2007). Fluorophore-conjugated phalloidin stains used were as follows: AF488phalloidin (Invitrogen), rhodamine-phalloidin (Invitrogen), and AF635phalloidin (Invitrogen). Secondary antibodies used were as follows: AF488conjugated goat-anti-mouse (Invitrogen), rhodamine-conjugated goatanti-rabbit (Jackson ImmunoResearch), Cy5-conjugated donkey-anti-goat (Jackson ImmunoResearch), and Cy2-conjugated donkey-anti-mouse
(Jackson ImmunoResearch). All samples were mounted in Fluoromont-G (SouthernBiotech) and sealed for long-term storage.

Whole-cell current patch-clamp recording. The flattened cochlear whole-mount preparation was used to record the hair cell whole-cell currents (Chang et al., 2008). Briefly, cochleae were isolated from the inner ears of either P5 or P6 male and female pups, and the lateral wall, Reissner's membrane, and tectorial membrane were removed from the duct. The organ of Corti and ectopic sensory region of $T g^{A t o h 1}$ samples were mounted on a glass coverslip. Ectopic and endogenous hair cells were identified by their specific location, shape, and presence of characteristic stereocilia as seen under differential interference contrast optics on a Zeiss AxioSkope 2. The external bathing solution was made from standard HBSS (H4891; Sigma), and internal solution components were as follows (in mM): $120 \mathrm{KCl}, 1.2 \mathrm{CaCl}_{2}, 1 \mathrm{MgCl}_{2}, 10 \mathrm{EGTA}$. The $\mathrm{pH}$ of the external and internal solutions was adjusted to 7.4 and 7.2, respectively, and the osmolarity was adjusted to $300 \mathrm{mOsm}$ for each. For potassium channel blockage experiments, $50 \mathrm{~mm}$ tetraethylammonium (TEA) was added to the recording solution. Traditional techniques for patchclamping hair cells were used as previously described (Housley and Ashmore, 1992). The electrode had an access resistance of $\sim 3 \mathrm{M} \Omega$. The whole-cell currents were recorded through an Axon 200B amplifier and Digidata 1322A (Axon), and only hair cells with a rupture resistance $\geq 500 \mathrm{M} \Omega$ were included for analysis. The current traces were analyzed using Clampfit 9.2 (Axon), and the associated current-voltage ( $I-V)$ curve was plotted using Origin 7.0 (OriginLab).

Imaging, cell counts, and statistical analysis. Mounted samples were imaged using either a IX71 inverted microscope (Olympus) with a highresolution monochrome AxioCam HRm camera (Zeiss) or they were scanned using a LSM510 confocal microscope (Zeiss). For DAPT/ DMSO-treated $\mathrm{Tg}^{\text {Atoh } 1}$ organ cultures, the percentage of hair cells was determined by calculating the number of MyoVI-positive cells over the 
total number of cells in the ectopic sensory region (see Fig. $6 D, F$ ). For quantification of the number of hair cells generated within the organ of Corti after extended Atoh1 induction, the sensory region defined by the most apical 100 inner hair cells was used as a standard unit domain among all samples. From within this domain in the endogenous outer hair cell area, the number of immature hair cells with rudimentary stereocilia bundles was counted, and these were compared between transgenic and control cochleae. Endogenous outer hair cells within this domain were also compared between transgenic and control samples to confirm that immature hair cells were, in fact, newly generated cells. All statistical comparisons were made using an unpaired two-tailed type 2 Student's $t$ test.

\section{Results}

Inducible $T g^{\text {Atoh } 1}$ expression produces new hair cells within the postnatal cochlea

To test the competency of postnatal cochlear epithelial cells to Atoh1-mediated hair cell differentiation, we generated inducible transgenic mice, $T g^{A t o h 1}$, in which the Atoh1 coding sequence is under the control of a tetracycline-response element (TRE). Atoh1 expression is activated by rtTA, which requires Dox to bind to the TRE and activate Atoh1 transcription (Fig. $1 A$ ). We verified the presence of the transgene in four founder lines (Fig. 1B) and selected the line (Founder 03) that carries an estimated two to three copies of the transgene for use in all subsequent experiments. To direct the expression of $T g^{\text {Atoh } 1}$ after the administration of Dox, we crossed $\mathrm{Tg}^{A t o h 1}$ mice with a Cre-activated $r t \mathrm{TA}$ line,

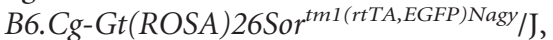

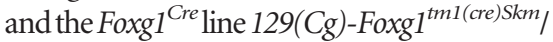
$\mathrm{J}$. We verified that rtTA expression was directed to the Foxg $1^{C r e}$-expessing cell population (Fig. 1C). Neonatal mice carrying all three transgenic alleles fed Dox for $2 \mathrm{~d}$ had a strong upregulation of Atoh1 transcript within the cochlear epithelium compared with normal levels expressed by littermate controls at postnatal day $2(\mathrm{P} 2)$ (Fig. $1 D)$. These triallelic transgenic mice, Foxg1 ${ }^{\mathrm{Cre}} ; \mathrm{rtTA} ; \mathrm{Tg}^{\mathrm{Atoh} 1}$, allowed targeted Atoh1 expression throughout the cochlear epithelium in a conditional and reversible manner dependent on the administration of Dox.

Forced ectopic delivery of Atoh 1 to cochlear epithelial cells has been shown previously to generate cells expressing hair cell markers (Zheng and Gao, 2000; Kawamoto et al., 2003; Shou et al., 2003; Woods et al., 2004; Izumikawa et al., 2005; Gubbels et al., 2008), and we observed a similar effect after Atoh 1 induction. Compared with littermate controls, induced triallelic $T g^{\text {Atoh } 1}$ mice had a large number of hair cells within the nonsensory Kölliker's organ region, or greater epithelial ridge (Fig. $2 A, B$ ), and isolated ectopic hair cells within the
Wildtype + Dox
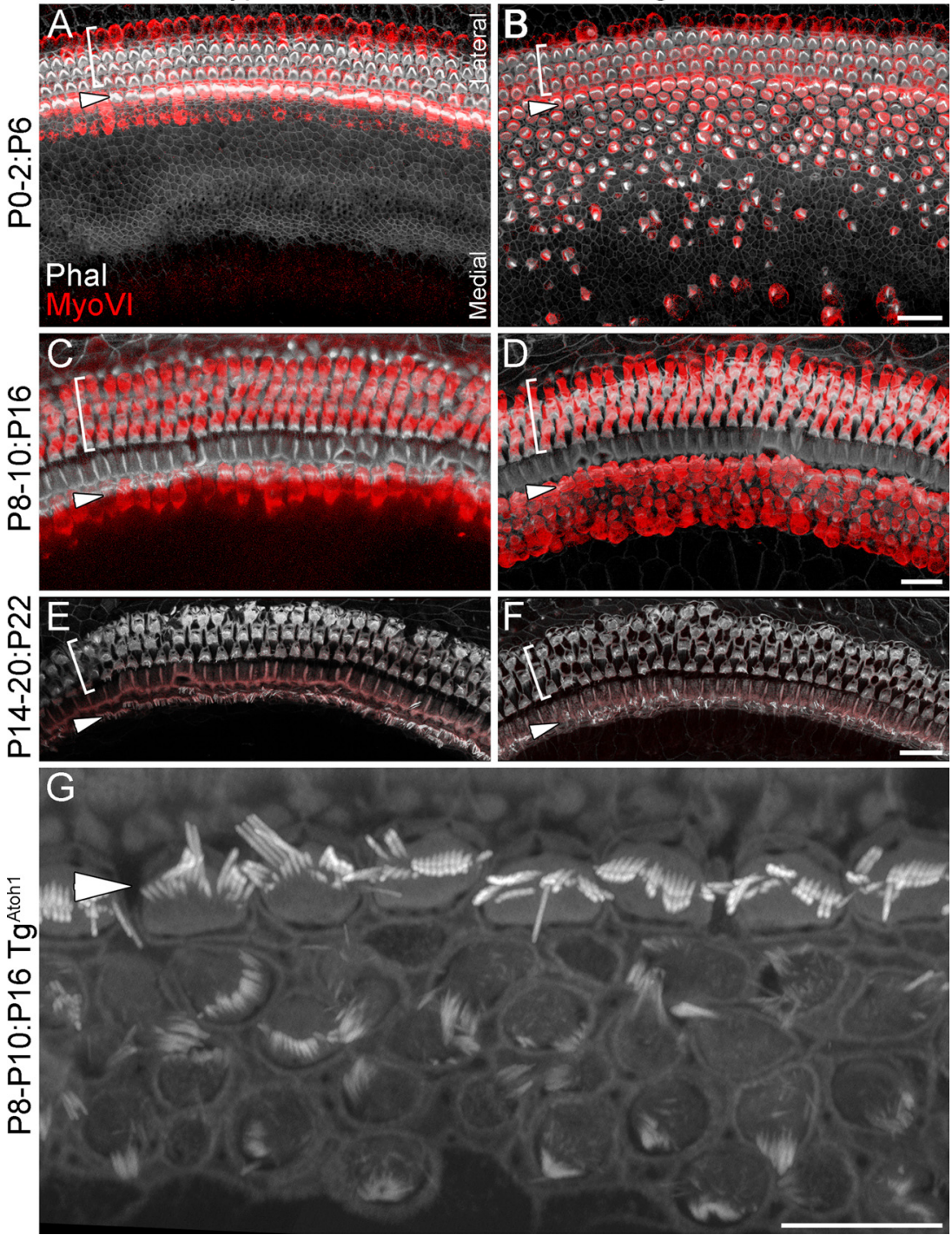

Figure 4. Regions competent for Atoh1-mediated hair cell differentiation decrease progressively with age. $\boldsymbol{A}-\boldsymbol{D}, A$ pical turn whole-mount cochleae from P6 stage $(\boldsymbol{A}, \boldsymbol{B})$ and P16 stage $(\boldsymbol{C}, \boldsymbol{D})$ mice administered Dox for $2 \mathrm{~d}(\mathrm{P} 0-\mathrm{P} 2: \mathrm{P} 6$ or P8 -P10:P16). Control littermates $(A, C)$ have a normal one row of inner and three rows of outer hair cells separated by the row of inner pillar cells (arrowhead). The triallelic $T g^{\text {Atoh1 }}$ cochleae had ectopic MyoVI-positive hair cells with stereocilia throughout Kölliker's organ is narrower in the older animals $(\boldsymbol{B}, \boldsymbol{D}), \boldsymbol{E}, \boldsymbol{F}$, Whole-mounts of $\mathrm{P} 22$ apical turn cochleae from mice administered Dox for an extended $6 \mathrm{~d}$ (P14-P20:P22) show no obvious differences between control $(\boldsymbol{E})$ and triallelic $\operatorname{Tg}^{\text {Atoh } 1}(\boldsymbol{F})$ mice. $\boldsymbol{G}$, High-resolution confoca cilia morphology in a mosaic cellular pattern surrounded by nonsensory cells. Scale bars: $\boldsymbol{B}($ for $\boldsymbol{A}, \boldsymbol{B}), \boldsymbol{D}($ for $\boldsymbol{C}, \boldsymbol{D}), \boldsymbol{F}($ for $\boldsymbol{E}, \boldsymbol{F}), 20$ $\mu \mathrm{m} ; \mathrm{G}, 10 \mu \mathrm{m}$. Phal, Phalloidin.

developing spiral prominence region on the lateral wall of the cochlea (Fig. $2 B$, arrow).

Sox 2 is normally expressed early in the entire sensory precursor domain and is subsequently downregulated within differentiating hair cells and maintained in nonsensory supporting cells during development (Kiernan et al., 2005a; Kelley, 2006; Dabdoub et al., 2008). Interestingly, Sox 2 appears to be induced in the ectopic hair cell region within the developing spiral prominence on the induction of Atoh1 (Fig. $2 B$, arrow). Furthermore, there appears to be an inverse relationship between the expression of the hair cell marker MyoVI and Sox2 within ectopic sensory regions (Fig. $2 B$, inset). This suggests that as new hair cells differentiate, they downregulate the expression of Sox 2 in a manner 

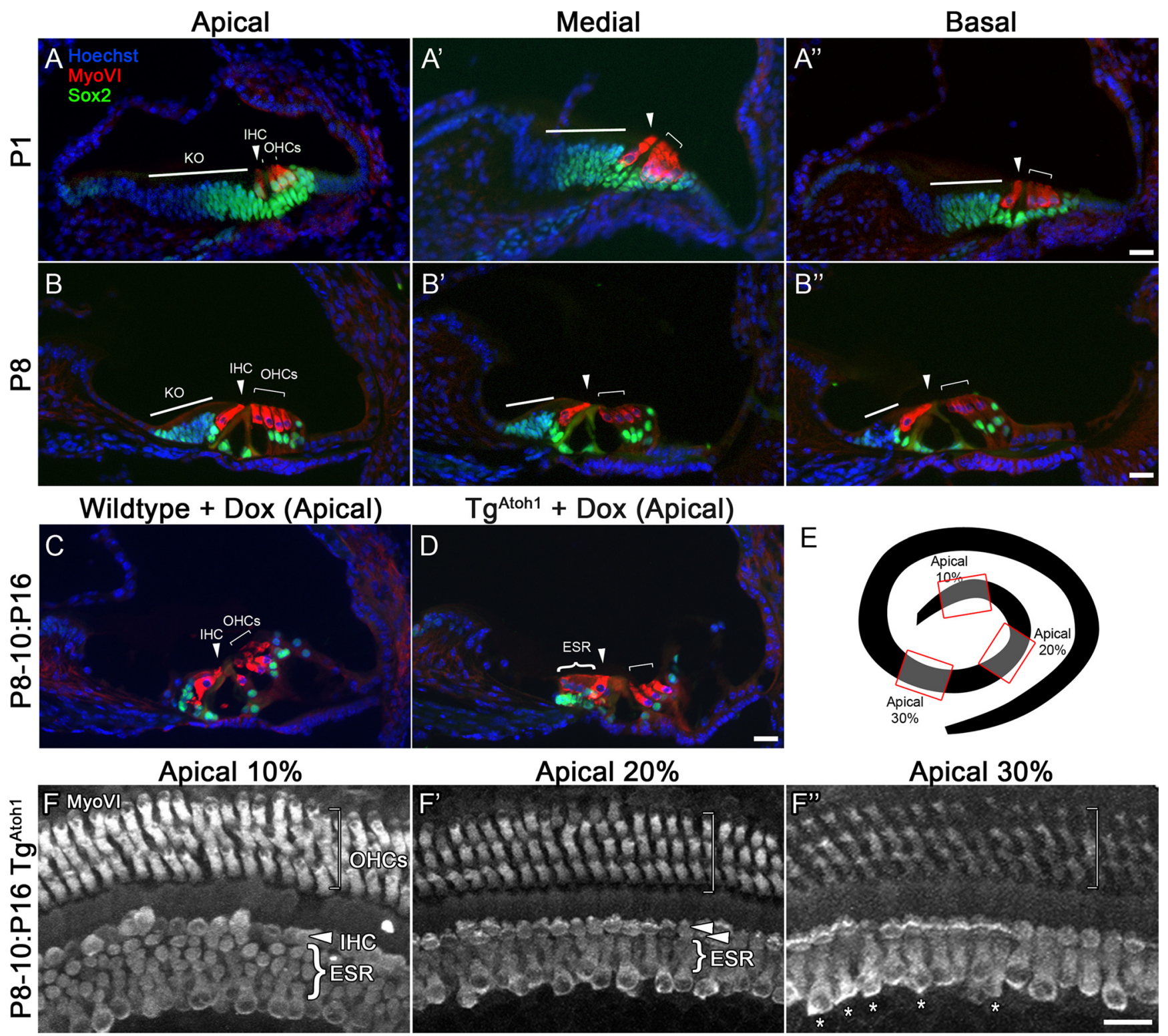

Figure 5. Age-dependent regional decrease in competency correlates with reduction of Sox2-positive cells in Kölliker's organ. $\boldsymbol{A}, \mathrm{Tg}^{\text {Atoh1 }}$-generated ectopic hair cells are generated in large numbers from the Sox2 expression domain, which extends throughout Kölliker's organ in P1 stage cochleae from apex to base $\left(\boldsymbol{A}-\boldsymbol{A}^{\prime \prime}\right)$. $\boldsymbol{B}$, The developmentally transient Kölliker's organ begins to disappear by $P 8$ in a basal $\left(\boldsymbol{B}^{\prime \prime}\right)$ to apical $(\boldsymbol{B})$ gradient that results in a loss of the Sox2-positive cell population. $\boldsymbol{C}$, P8 mice induced for $2 \mathrm{~d}$ and harvested at P16 (P8 -P10:P16) show ectopic hair cells only in the apical $\sim 30 \%$ in a domain that approximately corresponds to the Sox2-positive expression domain of Kölliker's organ at P8 (B). $\boldsymbol{D}$, Littermate control cochleae at the P16 stage have Sox2 expression limited to sensory region supporting cells $(\boldsymbol{D})$ and limited hair cell generation competency compared with earlier stages. $\boldsymbol{E}$, Diagram of regions competent in hair cell generation using the P8-P10 induction with analysis at P16 (P8-P10:P16). Sample regions shown in $\boldsymbol{E}$ are highlighted. $\boldsymbol{F}$, Sample whole-mount images of P8 -P10:P16 cochleae from the apical $\sim 10 \%(\boldsymbol{F})$, apical $\sim 20 \%\left(\boldsymbol{F}^{\prime}\right)$, and apical $\sim 30 \%\left(\boldsymbol{F}^{\prime \prime}\right)$, with ectopic sensory regions demarcated by brackets $\left(\boldsymbol{F}, \boldsymbol{F}^{\prime}\right)$ or isolated ectopic hair cells labeled by asterisks $\left(\boldsymbol{F}^{\prime \prime}\right)$. Scale bars: $\boldsymbol{A}^{\prime \prime}$ (for $\left.\boldsymbol{A}, \boldsymbol{A}^{\prime}, \boldsymbol{A}^{\prime \prime}\right), \boldsymbol{B}^{\prime \prime}\left(\right.$ for $\left.\boldsymbol{B}, \boldsymbol{B}^{\prime}, \boldsymbol{B}^{\prime \prime}\right)$, $\boldsymbol{D}($ for $\boldsymbol{C}, \boldsymbol{D}), \boldsymbol{F}^{\prime \prime}$ (for $\left.\boldsymbol{F}, \boldsymbol{F}^{\prime}, \boldsymbol{F}^{\prime}\right), 20 \mu \mathrm{m}$. ESR, Ectopic sensory region; IHC, inner hair cell; KO, Kölliker's organ; OHC, outer hair cell.

similar to the development of hair cells within the organ of Corti (Kiernan et al., 2005a; Kelley, 2006; Dabdoub et al., 2008).

Atoh1 induces morphologically and physiologically characteristic hair cells

We examined the morphology and physical properties of Atoh1induced hair cells. Ectopic hair cells produced within Kölliker's organ display stereocilia, which vary in maturity and have largely randomized orientation (Fig. $2 C, D$ ). In addition to MyoVI, these Atoh1-induced ectopic hair cells express hair cell marker parvalbumin and their hair bundles are espin positive (Fig. 2C,D). Ectopic hair cells attract Tuj1-positive neuronal fibers into Kölliker's organ region (Fig. 2E,F). These Tuj1-positive fibers appear to surround the basolateral surfaces of the ectopic hair cells in a manner similar to that of endogenous hair cells within the organ of Corti (Fig. 2F).

Atoh1 has been shown to generate new functional hair cells in ectopic and sensory regions (Izumikawa et al., 2005; Gubbels et al., 2008; Schlecker et al., 2011). We compared the passive basolateral currents of $T g^{\text {Atohl }}$-generated hair cells with endogenous organ of Corti hair cells by a whole-cell patch-clamp recording technique (Fig. $3 A-C$ ). The recorded current amplitudes from ectopic hair cells were smaller than those of endogenous outer hair cells (Fig. 3E-J). Nevertheless, ectopic hair cells exhibited several biophysical characteristics similar to those of their more mature endogenous counterparts (Fig. $3 E-J$ ). A blockade of 
TEA-sensitive potassium channels showed that voltage-dependent currents are similarly reduced in endogenous and ectopic hair cells (Fig. $3 E-J$ ), suggesting that comparable ion channels were expressed within the ectopic hair cells. There was also a striking similarity between endogenous and ectopic hair cells in the rising portion of the voltage-dependent current traces, which represent overall channel kinetics. This similarity suggests that ectopic hair cells express a similarly measurable population of ion channels.

\section{Competency for Atoh1-mediated hair} cell differentiation decreases with age and correlates with the reduction of Sox 2 expression domains

A relatively short, $2 \mathrm{~d} T g^{A t o h l}$ induction at the neonatal stage produces a large ectopic sensory region within Kölliker's organ and a small patch in the lateral wall (Figs. 2, $4 A, B)$. The Atoh1-mediated hair cell differentiation competency of various cell populations in the older postnatal cochlea, however, is not clear. Significant molecular and morphological changes occur in the mammalian cochlea during development, leading up to the onset of hearing (Hinojosa, 1977; Kelly and Chen, 2009; Reisinger et al., 2010).

We compared the competency of Atoh1-induced hair cell generation in $\mathrm{P} 0$, P8, and P14 cochleae (Fig. 4). We observed an ectopic sensory region limited to the most apical regions of the cochlea, just medial to the inner hair cell row, following a $2 \mathrm{~d} \mathrm{Tg}^{\text {Atoh1 }}$ induction in P8-stage mice (Fig. $4 C, D, G$ ), compared with the ectopic sensory region along the length of the cochlear duct in the neonatal cochlea (Fig. 4A,B). The competency was severely restricted by the $\mathrm{P} 14$ stage, and $T g^{A t o h 1} \mathrm{Co}-$ chleae were indistinguishable from controls, even with an extended $6 \mathrm{~d}$ induction paradigm (Fig. $4 E, F$ ). We noted that the progressively restricted competency of cells medial to the organ of Corti appears to correlate with a progressive narrowing of the Sox2-positive domain as Kölliker's organ undergoes its developmental regression to form the inner sulcus (Fig. 5) (Hinojosa, 1977).

Atoh1 induces the formation of cellular mosaic patterning via Notch signaling

Despite ubiquitous induction of Atoh1 in the Foxg1 ${ }^{\mathrm{Cre}}$-expressing cochlear epithelium (Fig. $1 C$ ), all ectopic sensory regions contained a mosaic pattern of hair cells and nonsensory cells (Figs. 2D, $4 B, G$ ). Notch signaling plays an important role during development to define the cellular mosaic pattern of the organ of Corti (Lanford et al., 1999; Kiernan et al., 2005b; Brooker et al., 2006; Takebayashi et al., 2007). Two Notch-associated downstream mediators known to inhibit hair cell differentiation during development, Hes1 and Hes5 (Zheng et al., 2000;
Zine et al., 2001; Li et al., 2008), were upregulated within $\mathrm{Tg}^{\text {Atoh } 1}$ cochleae after $2 \mathrm{~d}$ of induction (Fig. 6A).

To further explore the possibility that Notch signaling plays a role in patterning the ectopic sensory regions, we induced $T g^{\text {Atoh } 1}$ neonatal cochlear explant cultures while pharmacologically blocking Notch activity (Fig. $6 \mathrm{~B}$ ). In drastic comparison to the cellular mosaic pattern in the control cultures (Fig. 6C,D), cultures treated with DAPT, which inhibits $\gamma$-secretase-dependent cleavage of Notch required for downstream signaling (Geling et al., 2002), had an ectopic sensory region made up almost entirely of MyoVI-positive hair cells with only a few nonsensory cells throughout (Fig. 6E,F). Whereas DAPT treatment does not generate ectopic hair cells within Kölliker's organ in the wild-type cochlea, as reported previously (Doetzlhofer et al., 2009), the percentage of ectopic hair cells generated within Kölliker's organ of induced $\mathrm{Tg}^{\text {Atohl } 1}$ cochlear explants was significantly increased when cultured in the presence of DAPT (control DMSO treated, $22 \pm 11 \%$; DAPT treated, $66 \pm 13 \%$; $p<0.01 ; n=3$ ). DAPT treatment also caused a significant increase in the number of 
A

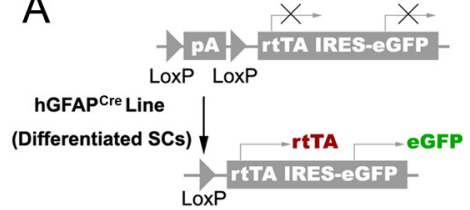

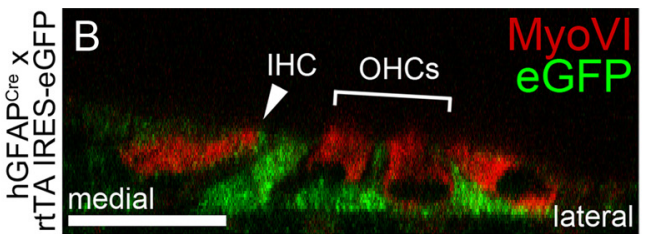

ateral
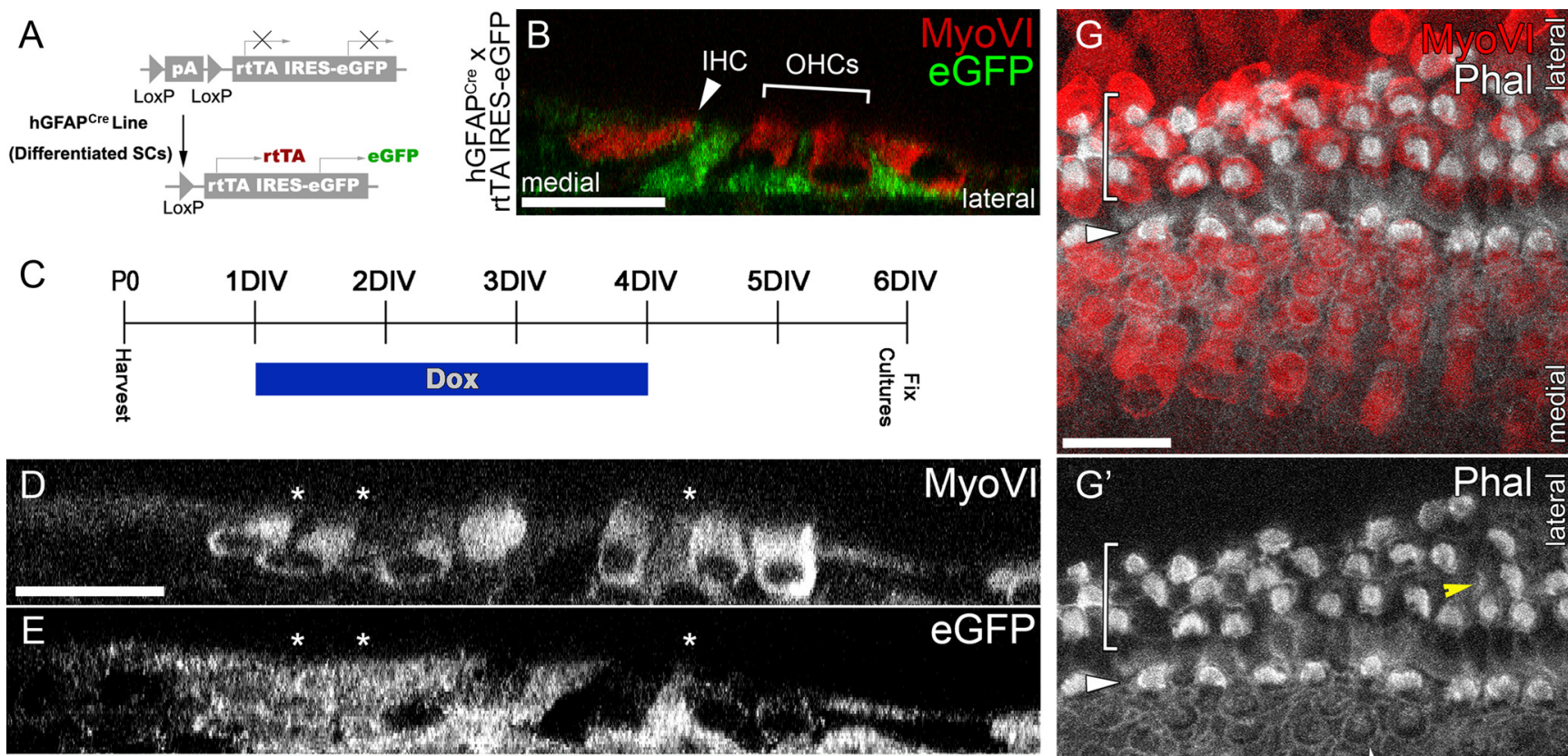

$\star$
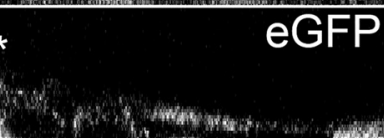

MyoVl

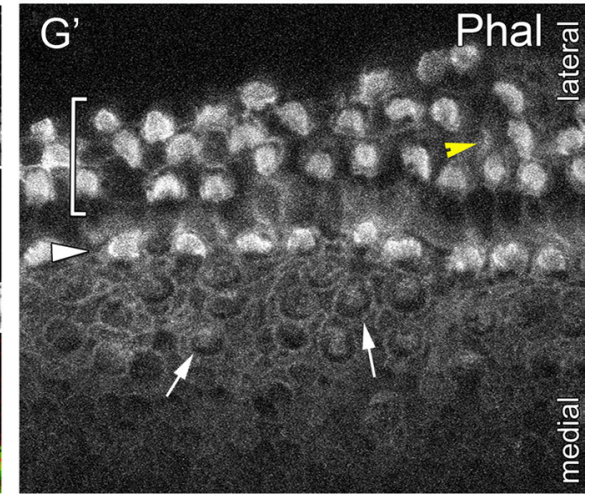

Figure 7. Differentiated supporting cells can be converted to new hair cells by directing Atoh1 to the supporting cells in culture. $A, B$, Diagram illustrates the activation of $r$ TTA within differentiated supporting cells using hGFAPCre ( $\boldsymbol{A})$. Cross section of the organ of Corti demonstrates GFP expression strictly in the supporting cells and excluded from MyoVI-expressing hair cells in GFAP(re, rtTA (eGFP) animals that are not fed with Dox. C, Diagram illustrating the induction protocol used. Doxycycline induction was maintained for $3 \mathrm{~d}$ between 1DIV and 4DIV for GFAP(re, $r t T A$ (eGFP); Tg Atoh1 animals. $\boldsymbol{D}-\boldsymbol{F}$, Orthogonal confocal sections taken through the cochlea after $3 \mathrm{~d}$ of Dox induction in GFAP(re, $r$ ITA (eGFP); $\mathrm{g}^{\text {Atoh } 1}$ animals. Note that a nascent MyoVI-positive cell within the organ of Corti (asterisk) is also positive for eGFP, suggesting its supporting cell origin. In addition, a few eGFP-positive and MyoVI-positive cells (asterisks) are observed in the medial region of the cochlear epithelium in which hGFAPCre is not detected initially, implicating a nonautonomous induction of new supporting cells and consequent expansion of the sensory mosaic. $\mathbf{G}, \mathbf{G}^{\prime}$, Phalloidin and MyoVI staining of the cochlear whole mount $(\boldsymbol{G})$ shows the production of ectopic hair cells with the formation of stereocilia bundles ( $\boldsymbol{G}^{\prime}$, arrows). A cell with an immature hair bundle within the sensory region is marked $\left(\boldsymbol{G}^{\prime}\right.$, yellow arrowhead). The brackets and arrowhead mark the $\mathrm{OHCs}$ and IHCs. Scale bars: $\boldsymbol{B}, \boldsymbol{D}$ (for $\left.\boldsymbol{D}-\boldsymbol{F}\right), \boldsymbol{G}$ (for $\left.\mathbf{G}, \boldsymbol{G}^{\prime}\right), 20 \mu \mathrm{m}$. DIV, Days in vitro; IHC, inner hair cell; IRES, internal ribosome entry site; $\mathrm{OHC}$, outer hair cell; Phal, phalloidin.

ectopic hair cells that were in direct contact with one another (DMSO treated, $23 \pm 4 \%$; DAPT treated, $95 \pm 5 \%$; $p<0.001$; $n=3)$.

$\mathrm{Tg}^{\text {Atoh } 1}$ expression induces expansion of the sensory mosaic through conversion of supporting cells and nonautonomous supporting cell production and stimulates ectopic cell proliferation

Although patterned ectopic sensory regions were readily generated in Kölliker's organ after a $2 \mathrm{~d} \mathrm{Tg}^{\text {Atoh1 }}$ induction in Foxg1 ${ }^{\mathrm{Cre}}$; $r t T A ; \mathrm{Tg}^{A t o h 1}$ triallelic mice, there appeared to be little effect on the nonsensory supporting cells within the organ of Corti (Figs. 2, 4). No newly differentiated hair cells were observed within the endogenous sensory region (Figs. $2 B, D, 4 B, D$ ). Despite having a shared expression of Sox 2 with Kölliker's organ (Figs. 2A, 5A, B), the postnatal supporting cells within the organ of Corti represent a distinct and highly differentiated cell population (Henderson et al., 1995; Slepecky et al., 1995; Kelly and Chen, 2007) that is specified and maintained by multiple signaling pathways (Fritzsch et al., 2002; Kelley, 2006; Doetzlhofer et al., 2009). To further test whether postnatal supporting cells can become hair cells, we crossed the $\mathrm{Tg}^{\text {Atohl } 1}$ line to GFAP ${ }^{\mathrm{Cre}}$ mice to direct $\mathrm{Tg}^{\text {Atohl } 1}$ expression specifically to differentiated supporting cells (Rio et al., 2002; Smeti et al., 2011) in vitro, where Cre expression in GFAP ${ }^{\mathrm{Cre}}$ mice was reliably observed (Fig. 7). Therefore, supporting cells can be lineage traced by Cre-activated enhanced GFP (eGFP) expres- sion. It appears that supporting cells within the organ of Corti can be activated to express an early hair cell marker, MyoVI (Fig. $7 D-F)$. In these GFAP ${ }^{C r e} ; r t T A(e G F P) ; \mathrm{Tg}^{A t o h 1}$-induced cochlear explant cultures, we also observed an expansion of the eGFP domain toward the region medial to the organ of Corti, where hair cell marker MyoVI expression can be detected and hair bundles are formed in this ectopically expanded sensory epithelium (Fig. 7). It has been reported that the generation of hair cells or the ectopic expression of Atoh1 induces the expression of a supporting cell marker, Jagged1, in surrounding cells (Woods et al., 2004). It is likely that the differentiation of hair cells in GFAPCre-positive cells induces a nonautonomous production of supporting cells and the expression of supporting cell markers, including GFAP, in the surrounding cells. The induction of GFAP leads to the induction of Atoh1 in these induced supporting cells, which are subsequently GFAP-Cre positive. The induction of Atoh1, in turn, activates hair cell differentiation and propagates the inductive events. It is also possible that GFAP-Cre may be endogenously expressed in the cells medial to the sensory region, often below detection levels.

We also explored whether longer $T g^{\text {Atoh } 1}$ induction could override the inhibitory signals and differentiated status of the cells that are less competent for hair cell induction by Atoh1 (Figs. $8,9)$. We administered Dox to neonatal Foxg1 ${ }^{\text {Cre }} ; r t T A ; \mathrm{Tg}^{\text {Atoh } 1}$ triallelic mice for $4 \mathrm{~d}$, compared with the routine $2 \mathrm{~d}$ administration. Within the organ of Corti, $T g^{\text {Atohl }}$-induced samples had 
Wildtype + 4d Dox
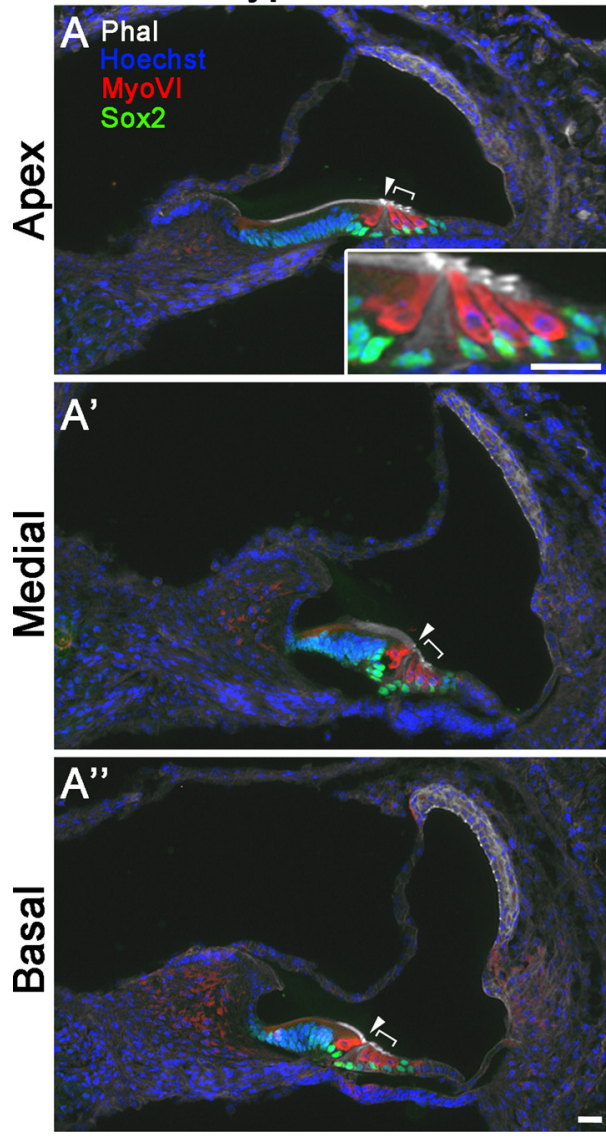

$\operatorname{Tg}^{\text {Atoh } 1}+2 d$ Dox
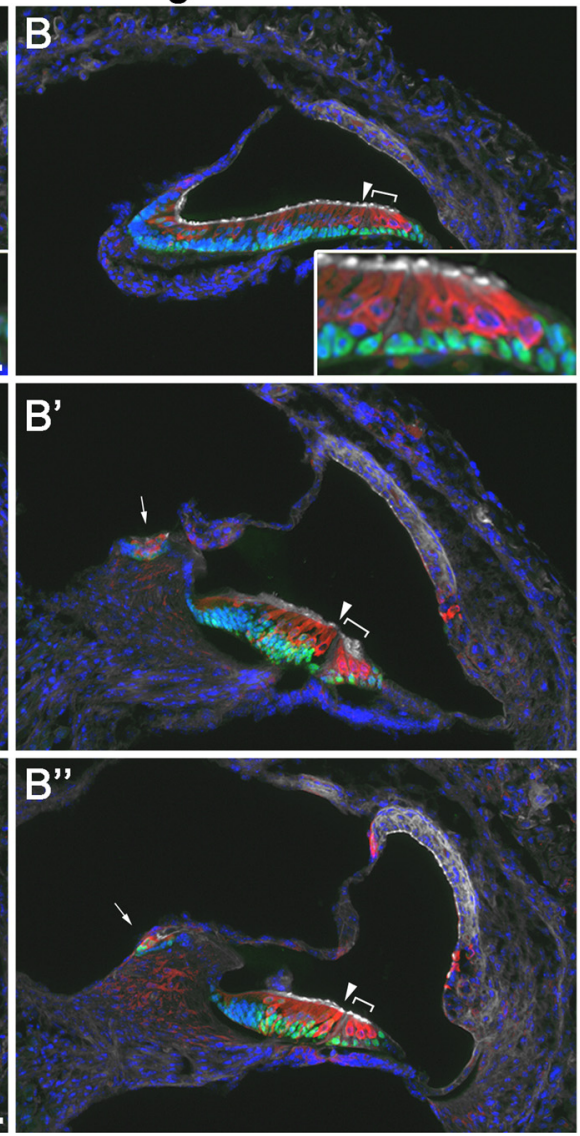

$\operatorname{Tg}^{\text {Atoh1 }}+$ 4d Dox
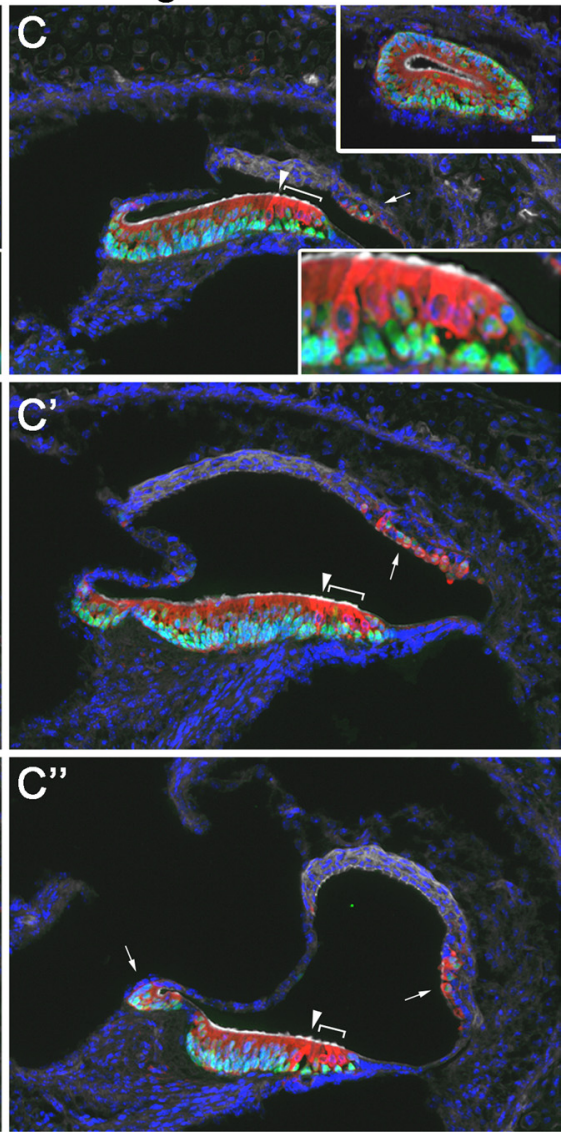

Figure 8. Extended Atoh1 induction greatly expands competency. $A, A^{\prime \prime}, \mathrm{P5}-\mathrm{P} 6$ stage control cochlea shows a stereotyped cellular architecture with one row of IHCs and three rows of $0 \mathrm{HCs}$ that run the length of the cochlear duct from apex $(\boldsymbol{A})$ to base $\left(\boldsymbol{A}^{\prime \prime}\right)$. Sox2 expression remains limited to the organ of Corti supporting cells and cells within Kölliker's organ. $\boldsymbol{B}, \boldsymbol{B}^{\prime \prime}, \mathrm{P5}-\mathrm{P} 6$ stage cochlea from a triallelic $T g^{A t o h 1}$ mouse administered Dox for $2 \mathrm{~d}(\mathrm{PO}-\mathrm{P} 2)$. Ectopic hair cells are limited primarily to an ectopic sensory region within Kölliker's organ and a small patch on the lateral wall that will develop into the spiral prominence region. $C, C^{\prime \prime}, P 5-P 6$ stage cochlea from a triallelic $T g^{\text {Atoh } 1}$ mouse administered Dox for $4 \mathrm{~d}$ (P0 -P4). The competency region within Kölliker's organ is expanded along the length of the cochlea. The very apical turn ( $\boldsymbol{C}$, inset) has a duct lined with MyoVI-positive hair cells. Note, however, that a layer of cells positive for Sox2 appears to remain $(\boldsymbol{C}$, inset). Scale bars: $\boldsymbol{A}$, bottom inset (for $\boldsymbol{A}-\boldsymbol{C}$, bottom insets), $\boldsymbol{C}$, top inset, $\boldsymbol{A}^{\prime \prime}$ (for $\boldsymbol{A}-\boldsymbol{A}^{\prime \prime}$ ), $\boldsymbol{B}^{\prime \prime}$ (for $\boldsymbol{B}-\boldsymbol{B}^{\prime \prime}$ ), $\boldsymbol{C}^{\prime \prime}$ (for $\boldsymbol{C}-\boldsymbol{C}^{\prime \prime}$ ), $20 \mu \mathrm{m}$. IHC, Inner hair cell; $0 \mathrm{HC}$, outer hair cell; Phal, phalloidin.

significantly disrupted patterning within the apical turn of the cochlea (Fig. 9A,B), with immature hair cells arising between endogenous hair cells and immediately lateral to the third row of outer hair cells (Fig. 9B). We quantified the number of immature hair cells arising within the outer hair cell domain, corresponding to the most apical region consisting of 100 inner hair cells. We found a significant increase in immature hair cells in transgenic compared with control cochleae $(44.3 \pm 24.9$ vs $2.0 \pm 1.73$; $p<$ 0.05; from three independent induction litters), whereas the number of endogenous outer hair cells was unchanged [353 \pm 14 (transgenic) vs $375 \pm 21.4$ (control); $p=0.21$ ], suggesting that cells with an immature hair bundle truly represented a newly generated population of hair cells. Outside the organ of Corti region, we also found expanded ectopic patches in Kölliker's organ and the lateral wall as well as MyoVI-positive cells along Reissner's membrane (Fig. 8). In the most apical region of the cochlear duct of these animals, we observed a cochlear epithelium composed almost entirely of MyoVI-positive hair cells (Fig. 8C, inset). Together, these results suggest that extended Atoh1 expression is capable of promoting hair cell differentiation in less competent cochlear epithelial cell populations.

In extended induction $\mathrm{Tg}^{\text {Atohl } 1}$ samples, we sometimes observed additional cells within the organ of Corti (Figs. 8, 9). These additional cells were presumably the product of either recruitment or induced cell proliferation in the normally postmitotic cochlear epithelium (Ruben, 1967; Chen and Segil, 1999; Chen et al., 2003). We tested whether proliferation was induced in response to Atoh 1 by injecting BrdU in $4 \mathrm{~d} \mathrm{Tg} g^{A t o h 1}$ induction pups to label S-phase nuclei (Fig. 9). Surprisingly, BrdU-positive nuclei were observed within the Hensen's or Claudius' cells of the Atoh1-induced organ of Corti (Fig. $9 A-F)$ and in other regions of the normally postmitotic cochlear epithelium (Ruben, 1967). One mechanism thought to maintain the postmitotic state of certain cochlear epithelial cells is the expression of cyclin-dependent kinase inhibitor Cdkn1b, formerly p27/Kip1 (Chen and Segil, 1999). In response to Atoh 1 induction, the expression of $C d k n 1 b$ is greatly reduced in the Hensen's and Claudius' cells, where ectopic cell proliferation is observed (Fig. 9E,F, arrows). $\mathrm{Tg}^{\text {Atoh } 1}$ stimulated proliferation was particularly apparent in cochlear explant cultures, where BrdU-positive nuclei were observed throughout the normally postmitotic sensory region domain (Fig. 9G,H). This enhanced cell proliferation in vitro may be due to unknown growth stimulators in the culture media or to the removal of physical restriction for tissue expansion.

To further confirm and characterize the Atoh1-induced cell proliferation events in culture, we immunostained Dox-treated 


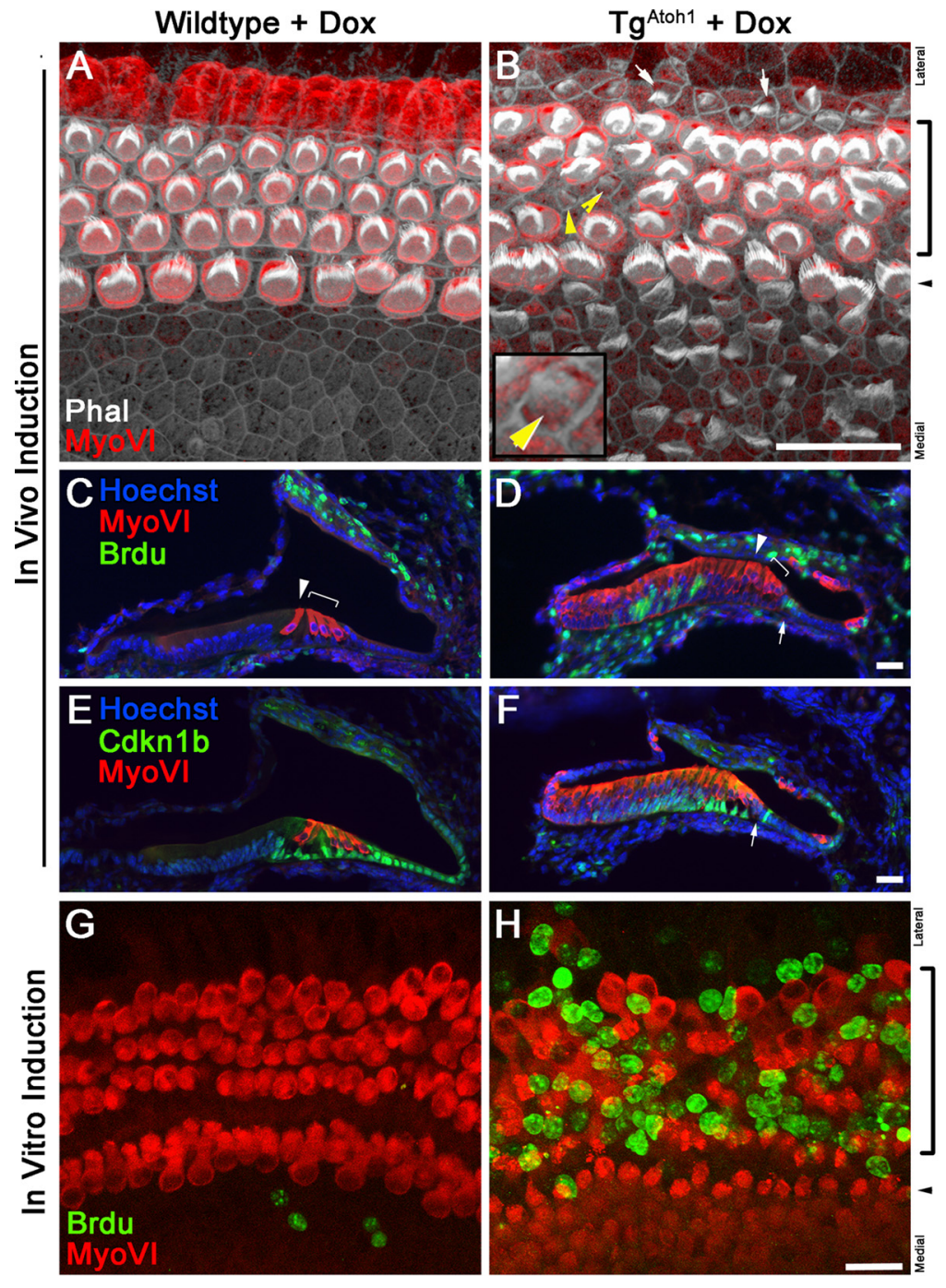

Figure 9. Extended Atoh1 induction induces cell proliferation in the normally postmitotic sensory domain. $\boldsymbol{A}, \boldsymbol{B}$, Whole-mount confocal images of apical turn cochlea from P5 stage mice administered Dox for $4 \mathrm{~d}$ (P0-P4). Compared with the stereotyped patterning of control littermates $(\boldsymbol{A})$, the sensory regions of Atoh1-induced mice show severe disruption $(\boldsymbol{B})$. Cells with immature hair bundles appear within the sensory region ( $\boldsymbol{B}$, yellow arrowheads). Inset $(\boldsymbol{B})$ shows a magnified image of an immature hair cell. In addition, ectopic hair cells are induced in the region immediately lateral to the third row of outer hair cells ( $\boldsymbol{A}$, arrows). $\boldsymbol{C}, \boldsymbol{D}$, Cross sections through the apical turn of cochlea from P5 stage triallelic $\mathrm{Tg}^{A t o h 1}$ mice administered Dox for $4 \mathrm{~d}(\mathrm{P0}-\mathrm{P} 4)$ and injected with BrdU daily. Compared with the normally postmitotic cochlear epithelium at P5 (C), the triallelic $T g^{\text {Atoh1 }}$ mice $(\boldsymbol{D})$ have a large number of BrdU-positive cells in Kölliker's organ and in the Hensen's and Claudius' cell population (arrows). E, F, Sections adjacent to those shown in $\boldsymbol{C}$ and $\boldsymbol{D}$, with changes in $\mathbf{C d k n 1 b}$, or p27/Kip1, expression in triallelic $T g^{A t o h 1}$ cochleae $(\boldsymbol{F})$ compared with littermate control cochleae $(\boldsymbol{E}) . \mathbf{G}, \boldsymbol{H}, \mathrm{P} 4$ stage cochlear organ cultures induced with Dox for $4 \mathrm{~d}$ in the presence of BrdU show no proliferation occurring in the sensory region of control cochleae $(\boldsymbol{G})$ but robust BrdU incorporation in the sensory region of $T g^{A t o h 1}$ cochleae $(\boldsymbol{H})$. The brackets and arrowheads mark the $\mathrm{OHC}$ and IHCs, respectively. Scale bars: $\boldsymbol{B}$ (for $\boldsymbol{A}, \boldsymbol{B}), \boldsymbol{D}($ for $\boldsymbol{C}, \boldsymbol{D}), \boldsymbol{F}($ for $\boldsymbol{E}, \boldsymbol{F})$, $\boldsymbol{H}$ (for $\boldsymbol{G}, \boldsymbol{H}), 20 \mu \mathrm{m}$. IHC, Inner hair cell; OHC, outer hair cell; Phal, phalloidin.

and control $T g^{\text {Atoh } 1}$ organ cultures for Sox 2 and the metaphase marker phospho-histone $\mathrm{H} 3$ (PH3) (Fig. 10). We found that whereas cultured littermate control cochlea had PH3 labeling below the Sox-2-positive supporting cell layer (Fig. 10C), many $\mathrm{PH} 3$-labeled cells were within the sensory layer and Sox2-positive in $\mathrm{Tg}^{\text {Atoh1 }}$ cochleae (Fig. $10 \mathrm{D}, \mathrm{E}$ ). Sox2-positive cells with $\mathrm{PH} 3$ localization consistent late-stage or completion of mitotic progression could be observed (Fig. 10D,E). Together, these results show that $T g^{A t o h 1}$ induction not only induces hair cell formation but also promotes cell cycle re-entry in the postnatal mammalian cochlear epithelium.

\section{Discussion}

Atoh1 has been established as a potent hair cell differentiation factor and remains a promising target for inducing endogenous cell populations toward regeneration of the mammalian auditory and vestibular sensory organ after damage. The potential of Atoh1-mediated regeneration extends beyond its role as simply a terminal differentiation factor because intriguing non-cell autonomous effects have been reported to induce supporting cell production adjacent to, and recruit innervation to, Atoh1-generated ectopic hair cells (Kawamoto et al., 2003; Woods et al., 2004; Gubbels et al., 2008). Despite the promise of Atoh1 in hair cell regeneration (Kawamoto et al., 2003; Izumikawa et al., 2005; Schlecker et al., 2011), a lack of genetic tools and the technical difficulty of targeted transfection of large numbers and specific types of cells in a reproducible manner prevent more extensive analysis to gain a realistic assessment of Atoh1 in hair cell regeneration.

Our novel Atoh1 transgenic mouse line provides a stable and flexible system for careful examination of Atoh 1 effects in various cell types of the cochlear epithelium at various stages. We show that a relatively short in vivo delivery of Atoh1 to the entire cochlear epithelium at the neonatal stage identifies distinct regions that are highly competent for hair cell differentiation (Fig. 2). Atoh1-generated hair cells are most robustly produced within the Kölliker's organ region and have characteristic hair cell properties (Figs. 2C, 3). These results suggest that the cells within Kölliker's organ at the neonatal stage retain competency to undergo an advanced hair cell differentiation program. In addition, we observed the production of ectopic hair cells in the lateral wall (Fig. 2), with short inductions of Atoh 1 and essentially the entire population of cells of the epithelium at the apical region of the cochlea with extended induction of Atoh1 (Fig. 9C, inset). These data together demonstrate the quantitative potency of Atoh 1 in hair cell induction and delineate the relative competency of various populations of cells.

Despite the induction of Atoh1 after the ubiquitous expression of rtTA in the cochlear epithelium (Fig. 1C), nonsensory cells persist and surround the ectopic hair cells within Kölliker's organ (Figs. 2 B, 4) through a Notch-dependent mechanism (Fig. 6). Although the effect of blocking Notch signaling is clear, there is some evidence that the cellular mosaic within the ectopic regions does not follow a strict model of contact-dependent Notch signaling lateral inhibition. Ectopic hair cells sometimes directly contact each other, and not all nonsensory cells surround ectopic 

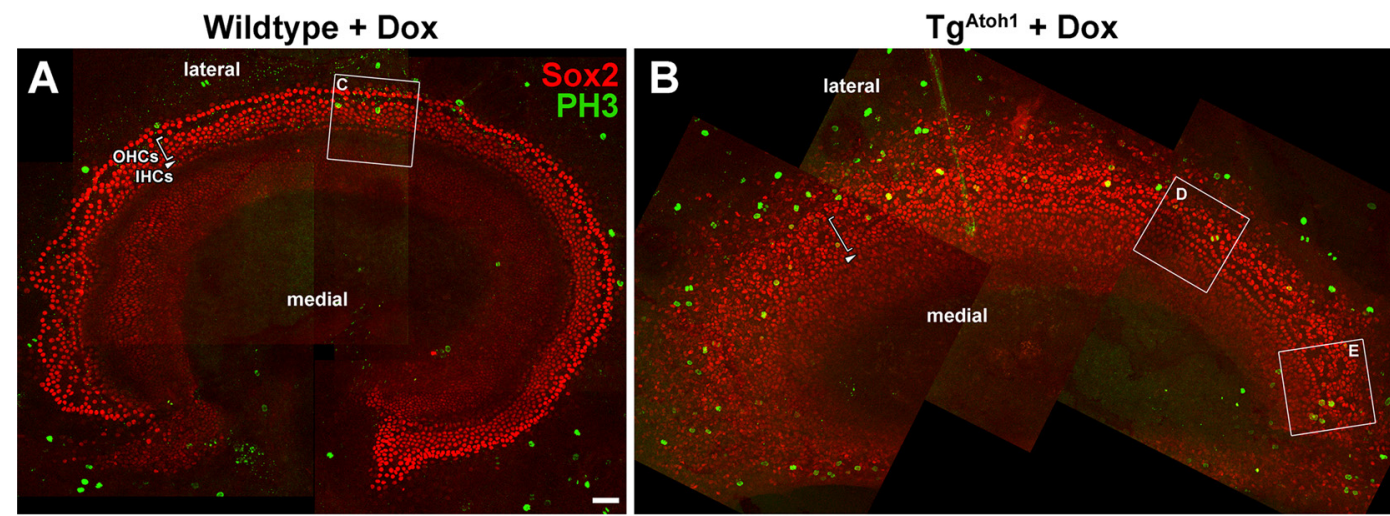

Wildtype + Dox
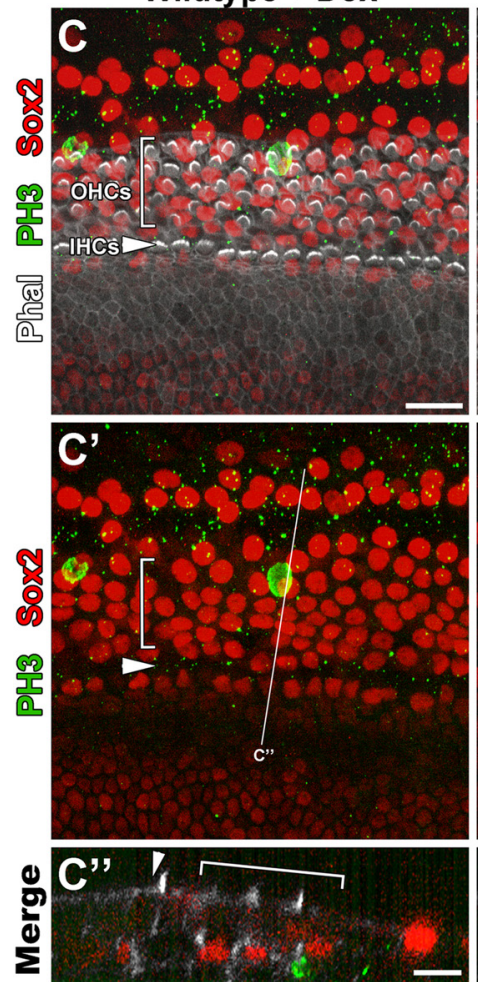

$\operatorname{Tg}^{\text {Atoh1 }}+$ Dox
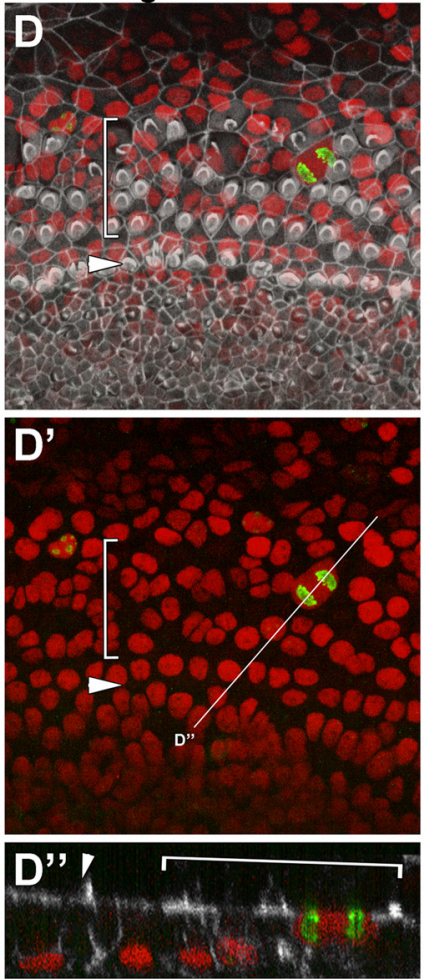

$\operatorname{Tg}^{\text {Atoh1 }}+$ Dox
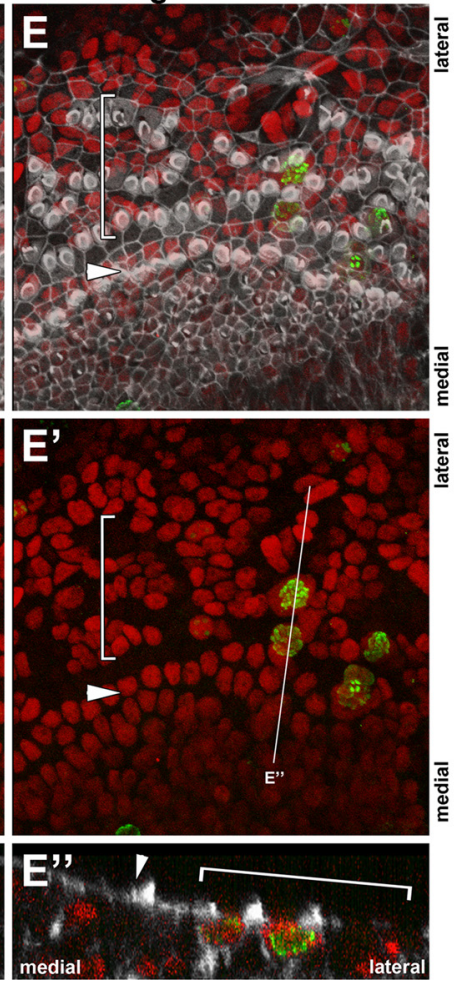

Figure 10. Mitotic supporting cells enter metaphase after extended Atoh1 induction. $\boldsymbol{A}, \boldsymbol{B}, \mathrm{P} 1$ stage apical turn cochlear explant cultures from wild-type littermate control $(\boldsymbol{A})$ and $T g^{\text {Atoh1 }}(\boldsymbol{B})$ treated with Dox for $4 \mathrm{~d}$. Epithelial and underlying mesenchymal cells in metaphase are labeled with phospho-histone $\mathrm{H3}$ (PH3). Brackets and arrowheads mark the $\mathrm{OHC}$ region and the IHC row, respectively. $\boldsymbol{C}-\boldsymbol{E}$, Higher-magnification confocal scans of regions identified with white outlines shown in $\boldsymbol{A}$ and $\boldsymbol{B}$. No Sox2-positive supporting cells (red) are observed to be PH3 positive (green) within the control sensory region, although clear staining can be seen within the underlying mesenchyme $\left(\boldsymbol{C}, \boldsymbol{C}^{\prime \prime}\right)$. In Atoh1-induced cochleae $\left(\boldsymbol{D}, \boldsymbol{D}^{\prime}, \boldsymbol{E}, \boldsymbol{E}^{\prime \prime}\right)$, many Sox2-positive nuclei (red) are positive for PH3 localization (green) that show supporting cells in various stages of metaphase and beyond, including cells in anaphase $\left(\boldsymbol{D}, \mathbf{D}^{\prime \prime}\right)$ and pairs of PH3-positive cells, suggesting completed mitosis $\left(\boldsymbol{E}, \boldsymbol{E}^{\prime \prime}\right)$. Orthogonal cuts through confocal scans show PH3-positive cells in control cultures are in Sox2-negative underlying mesenchymal cells $\left(\boldsymbol{C}^{\prime \prime}\right)$ and lumenal-localized Sox2/PH3-positive nuclei in $T g^{\text {Attoh1 }}$ samples $\left(\boldsymbol{D}^{\prime \prime}, \boldsymbol{E}^{\prime}\right)$. The white lines $\left(\boldsymbol{C}^{\prime}-\boldsymbol{E}^{\prime}\right)$ indicate the position of the corresponding orthogonal planes $\left(\boldsymbol{C}^{\prime}-\boldsymbol{E}^{\prime}\right)$. Scale bars: $\boldsymbol{A}$ (for $\left.\boldsymbol{A}, \boldsymbol{B}\right), 50 \mu \mathrm{m}, \boldsymbol{C}\left(\right.$ for $\left.\boldsymbol{C}-\boldsymbol{E}, \boldsymbol{C}^{\prime}-\boldsymbol{E}^{\prime}\right), \boldsymbol{C}^{\prime}$ (for $\left.\boldsymbol{C}^{\prime \prime}-\boldsymbol{E}^{\prime}\right)$, $20 \mu \mathrm{m}$. IHC, Inner hair cell; $\mathrm{OHC}$, outer hair cell.

hair cells (Fig. 6). As is the case in the development of the organ of Corti, additional pathways, such as FGF signaling (Mueller et al., 2002; Jacques et al., 2007; Puligilla et al., 2007) and Nectins (Togashi et al., 2006), may also be involved in patterning ectopic sensory regions. Together, these results suggest that multiple pathways are activated after Atoh1 delivery.

By comparing cochlear epithelia from $T g^{A t o h l}$ animals induced at P0, P8, and P14 stages, we show the competency to generate hair cells becomes progressively restricted over the postnatal time period during hearing onset (Fig. 4) and correlates with a regression of the Sox2-positive cells within Kölliker's organ (Fig. 5). This age-related decline in competency was also observed in an inducible Atoh1 transgenic mouse line generated by Jian Zuo's group, when expression is irreversibly activated at various postnatal time points (Liu et al., 2012). This change in competency illustrates the important distinction between generating new hair cells within embryonic and neonatal tissue and generating new hair cells within the adult cochlea, which presumably would be the primary target for hair cell regeneration.

Although highly competent Sox2-positive Kölliker's organ cells become increasingly limited during postnatal maturation, several possibilities for Atoh1-mediated hair cell generation in the more mature cochlea still exist. In triallelic $T g^{\text {Atoh } 1}$ cochleae, Sox 2 expression was observed in regions in which ectopic hair cells were generated outside Kölliker's organ (Figs. 2, 9). Additionally, organ of Corti supporting cells, which continue to ex- 
press Sox 2 but are not as easily converted under short induction protocols (Figs. 2, 4), can be converted with longer $T g^{A t o h l}$ induction (Figs. 7, $8 B$ ). These results suggest that longer Atoh1 delivery may be able to generate de novo sensory progenitors and convert less competent cell types. The extended Atoh1 induction required for conversion of supporting cells could be due to inhibitory signals important for maintaining the cellular pattern of the organ of Corti or the more differentiated status of these cell types. Because these supporting cells represent some of the most likely candidates for Atoh1-mediated hair cell generation, further work manipulating various signaling pathways is needed to more fully understand what limits the reprogramming of these cells.

Furthermore, cell cycle re-entry was observed in the normally postmitotic cochlear epithelium after extended Atoh1 induction. BrdU-positive nuclei are present in Hensen's or Claudius' cells in vivo (Fig. $8 D$, arrow) and within the sensory region in vitro (Fig. $8 H$ ). Dividing supporting cells are capable of progressing through mitosis, suggesting that they are not merely dying cells (Fig. 10). The observed proliferation is consistent with the idea that Atoh1 has varied roles, depending on the context of other signaling pathways (Klisch et al., 2011). It is possible that this phenomenon represents an attempt to repopulate cell populations that have been forcefully converted after extended Atoh1 delivery, and it may represent a mechanism of self-renewal similar to what has been reported within the avian auditory system (Cafaro et al., 2007).

Together, these findings illustrate the various effects of Atoh1 on the postnatal cochlea. In addition to confirming its known role as a potent hair cell differentiation factor, we show that Atoh1 can induce de novo expression of the prosensory factor Sox2 (Fig. 2) and nonautonomous induction of sensory hair and supporting cells (Fig. 7), and that it can promote cell cycle reentry under certain conditions (Figs. 9, 10) within the mammalian cochlear epithelium. Along with evidence that postnatally generated ectopic sensory regions retain the ability to form the correct cellular mosaic pattern, these results suggest that a functional sensory region may be regenerated in the mature animal, and they raise intriguing possibilities for hair cell regeneration. In combination with manipulations of other molecular pathways, the regulated induction of Atoh 1 in this transgenic line offers a promising opportunity to further test hair cell regeneration in mammals.

\section{References}

Belteki G, Haigh J, Kabacs N, Haigh K, Sison K, Costantini F, Whitsett J, Quaggin SE, Nagy A (2005) Conditional and inducible transgene expression in mice through the combinatorial use of cre-mediated recombination and tetracycline induction. Nucleic Acids Res 33:e51.

Bermingham NA, Hassan BA, Price SD, Vollrath MA, Ben-Arie N, Eatock RA, Bellen HJ, Lysakowski A, Zoghbi HY (1999) Math1: an essential gene for the generation of inner ear hair cells. Science 284:1837-1841.

Brigande JV, Heller S (2009) Quo vadis, hair cell regeneration? Nat Neurosci 12:679-685.

Brignull HR, Raible DW, Stone JS (2009) Feathers and fins: nonmammalian models for hair cell regeneration. Brain Res 1277:12-23.

Brooker R, Hozumi K, Lewis J (2006) Notch ligands with contrasting functions: Jagged 1 and Deltal in the mouse inner ear. Development 133:1277-1286.

Cafaro J, Lee GS, Stone JS (2007) Atoh1 expression defines activated progenitors and differentiating hair cells during avian hair cell regeneration. Dev Dyn 236:156-170.

Casper KB, McCarthy KD (2006) GFAP-positive progenitor cells produce neurons and oligodendrocytes throughout the CNS. Mol Cell Neurosci 31:676-684.

Chang Q, Tang W, Ahmad S, Zhou B, Lin X (2008) Gap junction mediated intercellular metabolite transfer in the cochlea is compromised in connexin30 null mice. PLoS One 3:e4088.

Chen P, Segil N (1999) p27(Kip1) links cell proliferation to morphogenesis in the developing organ of Corti. Development 126:1581-1590.

Chen P, Johnson JE, Zoghbi HY, Segil N (2002) The role of Math1 in inner ear development: uncoupling the establishment of the sensory primordium from hair cell fate determination. Development 129:2495-2505.

Chen P, Zindy F, Abdala C, Liu F, Li X, Roussel MF, Segil N (2003) Progressive hearing loss in mice lacking the cyclin-dependent kinase inhibitor Ink4d. Nat Cell Biol 5:422-426.

Dabdoub A, Puligilla C, Jones JM, Fritzsch B, Cheah KS, Pevny LH, Kelley MW (2008) Sox2 signaling in prosensory domain specification and subsequent hair cell differentiation in the developing cochlea. Proc Natl Acad Sci U S A 105:18396-18401.

Doetzlhofer A, Basch ML, Ohyama T, Gessler M, Groves AK, Segil N (2009) Hey2 regulation by FGF provides a Notch-independent mechanism for maintaining pillar cell fate in the organ of Corti. Dev Cell 16:58-69.

Forge A, Li L, Corwin JT, Nevill G (1993) Ultrastructural evidence for hair cell regeneration in the mammalian inner ear. Science 259:1616-1619.

Fritzsch B, Beisel KW, Jones K, Fariñas I, Maklad A, Lee J, Reichardt LF (2002) Development and evolution of inner ear sensory epithelia and their innervation. J Neurobiol 53:143-156.

Geling A, Steiner H, Willem M, Bally-Cuif L, Haass C (2002) A gammasecretase inhibitor blocks Notch signaling in vivo and causes a severe neurogenic phenotype in zebrafish. EMBO Rep 3:688-694.

Gubbels SP, Woessner DW, Mitchell JC, Ricci AJ, Brigande JV (2008) Functional auditory hair cells produced in the mammalian cochlea by in utero gene transfer. Nature 455:537-541.

Hébert JM, McConnell SK (2000) Targeting of cre to the Foxg1 (BF-1) locus mediates loxP recombination in the telencephalon and other developing head structures. Dev Biol 222:296-306.

Henderson CG, Tucker JB, Mogensen MM, Mackie JB, Chaplin MA, Slepecky NB, Leckie LM (1995) Three microtubule-organizing centres collaborate in a mouse cochlear epithelial cell during supracellularly coordinated control of microtubule positioning. J Cell Sci 108:37-50.

Hinojosa R (1977) A note on development of Corti's organ. Acta Otolaryngol 84:238-251.

Housley GD, Ashmore JF (1992) Ionic currents of outer hair cells isolated from the guinea-pig cochlea. J Physiol 448:73-98.

Izumikawa M, Minoda R, Kawamoto K, Abrashkin KA, Swiderski DL, Dolan DF, Brough DE, Raphael Y (2005) Auditory hair cell replacement and hearing improvement by Atohl gene therapy in deaf mammals. Nat Med 11:271-276.

Jacques BE, Montcouquiol ME, Layman EM, Lewandoski M, Kelley MW (2007) Fgf8 induces pillar cell fate and regulates cellular patterning in the mammalian cochlea. Development 134:3021-3029.

Kawamoto K, Ishimoto S, Minoda R, Brough DE, Raphael Y (2003) Math1 gene transfer generates new cochlear hair cells in mature guinea pigs in vivo. J Neurosci 23:4395-4400.

Kawamoto K, Izumikawa M, Beyer LA, Atkin GM, Raphael Y (2009) Spontaneous hair cell regeneration in the mouse utricle following gentamicin ototoxicity. Hear Res 247:17-26.

Kelley MW (2006) Regulation of cell fate in the sensory epithelia of the inner ear. Nat Rev Neurosci 7:837-849.

Kelley MW, Talreja DR, Corwin JT (1995) Replacement of hair cells after laser microbeam irradiation in cultured organs of Corti from embryonic and neonatal mice. J Neurosci 15:3013-3026.

Kelly M, Chen P (2007) Shaping the mammalian auditory sensory organ by the planar cell polarity pathway. Int J Dev Biol 51:535-547.

Kelly MC, Chen P (2009) Development of form and function in the mammalian cochlea. Curr Opin Neurobiol 19:395-401.

Kiernan AE, Pelling AL, Leung KK, Tang AS, Bell DM, Tease C, Lovell-Badge $\mathrm{R}$, Steel KP, Cheah KS (2005a) Sox 2 is required for sensory organ development in the mammalian inner ear. Nature 434:1031-1035.

Kiernan AE, Cordes R, Kopan R, Gossler A, Gridley T (2005b) The Notch ligands DLL1 and JAG2 act synergistically to regulate hair cell development in the mammalian inner ear. Development 132:4353-4362.

Klisch TJ, Xi Y, Flora A, Wang L, Li W, Zoghbi HY (2011) In vivo Atoh1 targetome reveals how a proneural transcription factor regulates cerebellar development. Proc Natl Acad Sci U S A 108:3288-3293.

Lanford PJ, Lan Y, Jiang R, Lindsell C, Weinmaster G, Gridley T, Kelley MW 
(1999) Notch signalling pathway mediates hair cell development in mammalian cochlea. Nat Genet 21:289-292.

Li S, Mark S, Radde-Gallwitz K, Schlisner R, Chin MT, Chen P (2008) Hey2 functions in parallel with Hes 1 and Hes 5 for mammalian auditory sensory organ development. BMC Dev Biol 8:20.

Liu Z, Dearman JA, Cox BC, Walters BJ, Zhang L, Ayrault O, Zindy F, Gan L, Roussel MF, Zuo J (2012) Age-dependent in vivo conversion of mouse cochlear pillar and Deiters' cells to immature hair cells by Atoh1 ectopic expression. J Neurosci 32:6600-6610.

Mueller KL, Jacques BE, Kelley MW (2002) Fibroblast growth factor signaling regulates pillar cell development in the organ of Corti. J Neurosci 22:9368-9377.

Puligilla C, Feng F, Ishikawa K, Bertuzzi S, Dabdoub A, Griffith AJ, Fritzsch B, Kelley MW (2007) Disruption of fibroblast growth factor receptor 3 signaling results in defects in cellular differentiation, neuronal patterning, and hearing impairment. Dev Dyn 236:1905-1917.

Qian D, Jones C, Rzadzinska A, Mark S, Zhang X, Steel KP, Dai X, Chen P (2007) Wnt5a functions in planar cell polarity regulation in mice. Dev Biol 306:121-133.

Reisinger E, Meintrup D, Oliver D, Fakler B (2010) Gene expression associated with the onset of hearing detected by differential display in rat organ of Corti. Eur J Hum Genet 18:1327-1332.

Rio C, Dikkes P, Liberman MC, Corfas G (2002) Glial fibrillary acidic protein expression and promoter activity in the inner ear of developing and adult mice. J Comp Neurol 442:156-162.

Ruben RJ (1967) Development of the inner ear of the mouse: a radioautographic study of terminal mitoses. Acta Otolaryngol 220 [Suppl]:1-44.

Schlecker C, Praetorius M, Brough DE, Presler RG Jr, Hsu C, Plinkert PK, Staecker H (2011) Selective atonal gene delivery improves balance function in a mouse model of vestibular disease. Gene Ther 18:884-890.

Shibata SB, Raphael Y (2010) Future approaches for inner ear protection and repair. J Commun Disord 43:295-310.

Shou J, Zheng JL, Gao WQ (2003) Robust generation of new hair cells in the mature mammalian inner ear by adenoviral expression of Hath 1. Mol Cell Neurosci 23:169-179.
Slepecky NB, Henderson CG, Saha S (1995) Post-translational modifications of tubulin suggest that dynamic microtubules are present in sensory cells and stable microtubules are present in supporting cells of the mammalian cochlea. Hear Res 91:136-147.

Smeti I, Savary E, Capelle V, Hugnot JP, Uziel A, Zine A (2011) Expression of candidate markers for stem/progenitor cells in the inner ears of developing and adult GFAP and nestin promoter-GFP transgenic mice. Gene Expr Patterns 11:22-32.

Takebayashi S, Yamamoto N, Yabe D, Fukuda H, Kojima K, Ito J, Honjo T (2007) Multiple roles of Notch signaling in cochlear development. Dev Biol 307:165-178.

Tang X, Falls DL, Li X, Lane T, Luskin MB (2007) Antigen-retrieval procedure for bromodeoxyuridine immunolabeling with concurrent labeling of nuclear DNA and antigens damaged by $\mathrm{HCl}$ pretreatment. J Neurosci 27:5837-5844.

Togashi H, Miyoshi J, Honda T, Sakisaka T, Takai Y, Takeichi M (2006) Interneurite affinity is regulated by heterophilic nectin interactions in concert with the cadherin machinery. J Cell Biol 174:141-151.

Warchol ME, Lambert PR, Goldstein BJ, Forge A, Corwin JT (1993) Regenerative proliferation in inner ear sensory epithelia from adult guinea pigs and humans. Science 259:1619-1622.

Woods C, Montcouquiol M, Kelley MW (2004) Math1 regulates development of the sensory epithelium in the mammalian cochlea. Nat Neurosci 7:1310-1318

Zheng JL, Gao WQ (2000) Overexpression of Math1 induces robust production of extra hair cells in postnatal rat inner ears. Nat Neurosci 3:580-586.

Zheng JL, Shou J, Guillemot F, Kageyama R, Gao WQ (2000) Hes1 is a negative regulator of inner ear hair cell differentiation. Development 127:4551-4560

Zine A, Aubert A, Qiu J, Therianos S, Guillemot F, Kageyama R, de Ribaupierre F (2001) Hes1 and Hes5 activities are required for the normal development of the hair cells in the mammalian inner ear. J Neurosci 21: $4712-4720$. 